\title{
Research Paper: Postpartum Depression and Physical Activity Among Women Attending Postnatal Clinics in a Tertiary Hospital in Nigeria
}

\author{
Nwosu Netochi Georgiana ${ }^{1^{*}}$ (i)
}

1. Department of Community Medicine, Faculty of Public Health, University of Ibadan, Ibadan, Nigeria.

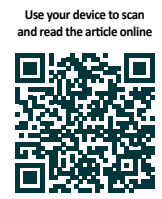

dtation Netochi Georgiana N. Postpartum Depression and Physical Activity Among Women Attending Postnatal Clinics in a Tertiary Hospital in Nigeria. Journal of Research \& Health. 2021; 11(5):285-296. http://dx.doi.org/10.32598/JRH.11.5.1915.1

doi http://dx.doi.org/10.32598/JRH.11.5.1915.1

\section{(i) (\$)}

Article info:

Received: 22 Jun 2021

Accepted: 31 Jul 2021

Publish: 01 Oct 2021

\section{Keywords:}

Postpartum depression, Women, Physical activity, Edinburgh postpartum depression scale, Nigeria

\section{A B S T RACT}

Background: The reproductive years come with their own share of mental health issues with childbirth and the postpartum period being a particularly vulnerable time for mothers leading to an increase in the risk of depressive disorders. Postpartum depression has a huge public health effect on the mother with long-term consequences on the child and family. Research has shown that physical activity is beneficial; however, such studies are lacking in Nigeria. Therefore, this study sought to look at the association between postpartum depression and physical activity and determine its prevalence among women in a tertiary hospital in Nigeria.

Methods: This cross-sectional study was conducted among 401 women attending immunization and postnatal clinics at the University College Hospital Ibadan. The data were collected using a self-administered questionnaire containing a self-developed socio-demographic section, Edinburgh postnatal depression scale to measure postpartum depression, and an International physical activity questionnaire (short type) to as sess physical activity. Analysis was done using the Chi-square test and multivariate analysis to determine independent factors. Significance was set at 0.05 .

Results: More than a third of the respondents (37.8\%) had postpartum depression. Physical activity level was high (72.1\%). High levels of physical activity increased the odds of postpartum depression compared to lower levels $(95 \% \mathrm{CI}=0.797-0.97)$. Gender of the child, marital relationship satisfaction, and age of the child were independently associated with postpartum depression.

Conclusion: This study showed that the prevalence of postpartum depression is greater than previously reported in past studies in southwest Nigeria and high levels of physical activity may increase the risk of postpartum depression.

\footnotetext{
"Corresponding Author:

Nwosu Netochi Georgiana, PhD.

Address: Department of Community Medicine, Faculty of Public Health, University of Ibadan, Ibadan, Nigeria.

Phone: +234 (905) 0523032

E-mail: netochinwosu@gmail.com
} 


\section{Introduction}

A

mong all common mental health disorders, depression is the most common illness affecting people and by the year 2020 , it was expected to be the second most prevalent health problem worldwide [1]. In 2017, the World Health Organisation estimated that about $9 \%$ of the over 320 million people living with depressive disorders were in Africa [2]. Among women of reproductive age, depressive disorders lead universally. Due to the greater prevalence of depression among females compared to males, maternal mental health has become a vital public health issue and poses a challenge across the globe. The most common mental health challenge Post-childbirth is Postpartum Depression (PPD), an overwhelming illness that impairs maternal behavior [3]. PPD is classified as a major depressive episode that begins within 4 or 6 weeks of childbirth by the Diagnostic and Statistical Manual of Mental Disorders and 10th edition of the International Classification of Diseases, respectively [4]. Although the onset must be within 4-6 weeks, it is believed that women remain exposed to the risk of PPD even up to 14 months after delivery $[5,6]$.

It has been reported that it affects around 1 in 10 women at some time in the first year [7], studies have shown a diverse and higher range of PPD prevalence. Norhayati et al. in a review of the literature reported a prevalence of about $0 \%$ to almost $60 \%$ from one continent to another [3], while HahnHolbrook et al. in a large meta-analysis reported a global prevalence of $17.7 \%$ [8]. A literature review on lower-middle-income countries has placed the prevalence of PPD at approximately $20 \%$ [9]. According to studies conducted in Nigeria, about $10 \%-30 \%$ of women attending primary care have PPD [10]. However, Abiodun in a similar population reported a prevalence of $18.6 \%$ in developing societies [11].

Several psychological, biological, and social factors have been fingered in the etiology of PPD and have shown positive association. Psychosocial risk factors, such as a history of depression, poor relationship with spouse, weak social support, stressful periods/events prior to birth, poor social status, the stress of childcare, and complications during birth have been strongly associated with PPD [3, 4, 12]. General treatment of PPD includes medication and psychotherapy. Side effects of these drugs however are relatively unknown, especially as it relates to its effects in breast milk $[13,14]$ coupled with reports on relapse and other adverse effects [15]. Hence non-pharmacologic approaches are highly recommended given maternal reluctance.
In Nigeria, not every mother can afford the drugs, or the cost of psychotherapy given the socioeconomic terrain, whereas physical activity is easily accessible, affordable, and has fewer side effects. Considering the effect of PPD, physical activity should be considered and encouraged. As reported by Kołomańska-Bogucka and Mazur-Bialy in a review of the literature, physical activity is an important part of preventing PPD [16]. Furthermore, studies have shown that participation in some forms of physical activity (leisure time activity or moderate to vigorous activity) improves PPD symptoms [17-20]. However, there is a dearth of such research in Nigeria. To the best of my knowledge, no study has explored the relationship between physical activity and PPD in Nigeria, prompting this study whose main objectives were to determine the prevalence of PPD and the relationship between physical activity and PPD. Other objectives included determining other risk factors in PPD.

\section{Methods}

\section{Participants}

This cross-section study was carried out at the University College Hospital, which is a multidisciplinary tertiary hospital in Ibadan attending to a mix of patients from all over. The target population of the study was infant nursing mothers that came for immunization at the child welfare clinic of the Institute of Child Health and Postnatal Clinic at the University College Hospital, Ibadan. Mothers who had a delivery within the 12 months preceding this study, who were at least four weeks post-delivery were included. Women who were pregnant were excluded.

\section{Study design}

The total sampling method was employed for this study. This was due to the number of women attending the child welfare and postnatal clinics, which was about 300 women per month, and the study duration, which was scheduled for six weeks. All consenting respondents available during the six weeks duration of this study were surveyed until the required study size was achieved. The study sample size was determined using the Leslie Kish Formula 1:

$$
\text { 1. } n=\frac{Z \alpha^{2} p q}{d^{2}}
$$

Where, $\mathrm{P}=30.6 \%, \mathrm{q}=69.4 \%, \mathrm{Z} \alpha=$ standard normal deviate corresponding to $95 \%$ confidence interval, critical value of 1.96 , and $\mathrm{d}=0.05$.

Using a previously reported prevalence of $30.6 \%$ in a Nigerian study [21], the sample size was calculated to 
be 326 . Using a $10 \%$ anticipated non-response rate, the sample size was rounded up to 400 . In totality, 401 women participated in the study.

\section{Data collection}

The questionnaire, which was filled by the respondents was in English language and consisted of three sections.

A) Socio-demographic section: containing personal information (age, religion, tribe, educational status, marital status, family type, employment status, and occupation), family and social history (number of children, ever lost a child, help with the child, relationship satisfaction, agreement with the partner on finance, decision making, and finance), child and obstetric history (age of the present child, illness during pregnancy, mode of delivery, desired gender, complications during pregnancy, and history of depression).

B) The Edinburgh Postnatal Depression Scale (EPDS): The scale, which consists of 10 questions, asks the respondent how they have been feeling over the last one week. Responses are ranked from 0 to 3, according to severity, with an overall score of 30 . This study used a score of 10 as its cut-off for PPD. This score has been suggested for the detection of mild depression [22]. As reported by Adewuya et al., "at a cut-off score of 10, the EPDS was found to be the best for screening for both major and minor depression (sensitivity $=0.867$, specificity $=0.915$, and diagnostic likelihood ratio for a positive result=10.200)" [22].

C) International Physical Activity QuestionnaireSF (IPAQ): It consists of seven questions that measure individuals' past 7-day levels of physical activity. This scale measures the various intensities of physical activity that people do as part of their daily activities and time spent sitting and estimates total physical activity in Metabolic Equivalent of Task (MET) per min/week and estimates sitting time. The types of activity assessed were walking, moderately intense activities, and vigorous activities. The categorical scoring method classifies physical activity into low, moderate, or high according to the number of hours and days spent in moderate or vigorous physical activities and walking. The examples of physical activities given in the IPAQ were fine-tuned to reflect activities that are common to this environment and were validated by a content expert (physiotherapy department). The activities were chosen from the compendium of physical activities and had the same metabolic equivalent of the task as the original activities given. Categorical scoring was graded as:
Low-no activity: some activities are reported but not enough to meet categories 2 or 3 .

Moderate: any of the following three criteria: three or more days of vigorous activity for at least 20 minutes per day or five or more days of moderate-intensity activity and/or walking of for least 30 minutes per day or five or more days of any combination of walking, moderateintensity, or vigorous-intensity activities achieving a minimum of at least $600 \mathrm{MET}$-minutes/week

High: any one of the following two criteria: Vigorousintensity activity for at least three days and accumulating at least $1500 \mathrm{MET}$-minutes/week or seven or more days of any combination of walking, moderate- or vigorousintensity activities accumulating at least 3000 MET-minutes/week" (http://www.ipaq.ki.se).

IPAQ has shown to be appropriate for use in developed or developing countries and has good evidence of testretest reliability [23].

\section{Data analysis}

Data were analyzed using SPSS version 20. Data collected at the end of each day was checked for errors and cleaned. Questionnaires with missing data were discarded. A research assistant was present to help with any difficulties the respondents encountered. Data were categorized into women with EPDS scores above 10 as having symptoms of depression and below 10 as not having depressive symptoms. Physical activity was categorized as low, moderate, or high.

Descriptive statistics, such as frequencies and percentages were used to summarize and present the prevalence of PPD, PA, and risk factors, such as demographic, family, obstetric, and maternal variables. Relationship satisfaction was determined from three questions, which were picked from the couple satisfaction index; 'in general, how often do you think things are going on well between you and your partner?, do you feel like a team with your partner?, and does your partner meet your needs'? Responses were ranked on a Likert scale of 0-5 and summed up to 15 . Relationship satisfaction was categorized as poor (0-5), moderate (6-10), and good (11$15)$. The Chi-square test was used to determine the association between PPD (dependent variable) and physical activity (independent variable). Bivariate analysis was also performed to explore risk factors (independent variables) that were significantly associated with PPD at a significance level of $10 \%$. Logistic regression was performed for all significant variables from the bivariate analysis to determine the odds ratio and $95 \% \mathrm{CI}$ at a significance level of $5 \%$. 


\section{Results}

From a total of 600 women proposed to participate, 401 women willingly participated. Almost half of the women $(43.1 \%)$ were within the age range of $30-34$, while about $27 \%$ were above 35 years. The Mean \pm SD age of respondents was $31.8 \pm 4.1$, with the age range of $20-50$ years. Most were Yoruba (88\%), the dominant ethnic tribe of Southwest, Christian (84\%), and tertiary education (79.6\%). Three-quarters of the respondents had less than two children (76.5\%), and $32.9 \%$ had a child aged between three months and six months. Half had some sort of childcare support and almost all had their desired gender at birth $(86.3 \%)$ and were in monogamous marriages $(83.3 \%)$. Most of the respondents agreed with their partners on major decisions (87.3\%), issues concerning finances (88\%), and in-laws (79.8\%). Also, most of the respondents reported satisfaction with their relationship with their partners $(85.8 \%)$. Two-third of the respondents were healthy during pregnancy $(78.6 \%)$, while almost all had no complications at birth (92.5\%). About 59.7\% of respondents had a normal delivery and less than $10 \%$ had a medical history of depression (Table 1).

Prevalence of postpartum depression and physical activity

The prevalence of PPD was $37.8 \%$. The Mean \pm SD PPD score was $8.15 \pm 4.7$ with scores ranging from 0 26. Suicidal ideation was reported by 31 women $(7.7 \%)$ who answered above 1 to the tenth question of the EPDS scale. Physical activity was generally high. Among the women, $41.2 \%$ had moderate levels of physical activity and $30.9 \%$ had higher levels of physical activity. In general, $72.1 \%$ of respondents were physically active, while $27.9 \%$ had low/no physical activity.

\section{Postpartum depression and physical activity}

There was no statistically significant association between PPD and physical activity $(\mathrm{P}=0.327)$, but those with higher physical activity had an increased risk of having PPD $(\mathrm{OR}=$ $1.255,95 \% \mathrm{CI}=0.797-0.977)$ (Table 2).

\section{Postpartum depression and other variables}

Family type $(\mathrm{P}<0.001)$, age of the child $(\mathrm{P}=0.025)$, number of children living $(\mathrm{P}=0.019)$, and desired gender $(\mathrm{P}=$ $0.026)$ were statistically associated with $P P D$. Maternal age $(\mathrm{P}=0.912)$, support for childcare $(\mathrm{P}=0.220)$, previously lost a child $(\mathrm{P}=0.413)$, and marital status $(\mathrm{P}=0.156)$ were not statistically associated with PPD (Table 2). Medical history of depression pre-pregnancy was significantly associated with PPD $(\mathrm{P}=0.086)$. Agreement with the partner on family finances $(\mathrm{P}=0.026)$, ways to deal with in-laws $(\mathrm{P}=0.008)$, decision-making $(\mathrm{P}=0.008)$, and marital relationship satisfaction $(\mathrm{P}<0.001)$ were also significantly associated with PPD (Table 3 ).

\section{Multiple regression}

High physical activity increased the odds of PPD compared to low physical activity $(\mathrm{OR}=1.14 ; 95 \% \mathrm{CI}=0.625$ 2.096), but this was not statistically significant. Age of child was statistically associated with PPD. Mothers with a child aged between 6 weeks and 3 months were independently associated with $\mathrm{PPD}(\mathrm{OR}=0.24 ; 95 \% \mathrm{CI}=0.06$ 0.89 ). Women with children aged between 6 and weeks 3 months were at less risk of PPD than women with children aged older than nine months. The family type had a statistically independent significant association with PPD.

Women who were in polygamous marriages were three times more likely to have PPD than those that were in the monogamous family $(\mathrm{OR}=3.49 ; 95 \% \mathrm{CI}=1.83-6.65)$ and single parents were less likely $(\mathrm{OR}=0.66 ; 95 \% \mathrm{CI}=$ 0.14-3.06). Women who reported having the desired gender were also less likely $(\mathrm{OR}=0.47 ; 95 \% \mathrm{CI}=0.24-0.93)$ to report PPD symptoms than those who did not have their desired gender. Relationship satisfaction was independently associated with $\mathrm{PPD}(\mathrm{OR}=2.664$; 95\%CI $=$ 1.317-5.390). Those with poor/ moderate relationship satisfaction were twice as likely to have PPD than those in a good relationship with a partner (Table 4).

\section{Discussion}

This study showed a high prevalence $(37.8 \%)$ of PPD, which is comparable to some other Nigerian studies done in a similar hospital setting [21-24]. In Nigeria, varying rates from $10-44 \%$ have been reported from different regions of the country [22, 25-27]. This wide range of prevalence is also reflected in Africa as well as other continents [28]. However, the majority of developing countries have a higher estimated prevalence than that found in high-income countries [3, 29, 30]. This variability from country to country could be due to study design (diagnostic tool, cut-off scores, and period of assessment), cross-cultural differences, socio-economic terrain, and perception of PPD/ mental health. This further indicates that a woman's susceptibility to PPD is not based on geographical location but on social, economic, psychological, and biological factors that thrive in enabling environments.

With three-quarters of the women reporting moderate to high physical activity, the prevalence of physical 
Table 1. Descriptive data for socio-demographic factors $(n=401)$

\begin{tabular}{|c|c|c|}
\hline \multicolumn{2}{|l|}{ Variables } & \multirow{2}{*}{$\begin{array}{c}\text { No. (\%) } \\
11(2.7)\end{array}$} \\
\hline \multirow{4}{*}{ Mother's age } & $<25$ & \\
\hline & $25-29$ & $106(26.4)$ \\
\hline & $30-34$ & $173(43.1)$ \\
\hline & $\geq 35$ & $111(27.7)$ \\
\hline \multirow{3}{*}{ Religion } & Christian & $337(84)$ \\
\hline & Islam & $63(15.7)$ \\
\hline & Others & $1(0.3)$ \\
\hline \multirow{3}{*}{ Ethnic group } & Yoruba & $354(88.3)$ \\
\hline & Igbo & $20(4.8)$ \\
\hline & Others ${ }^{*}$ & $27(6.9)$ \\
\hline \multirow{4}{*}{ Educational status } & Primary & $1(0.2)$ \\
\hline & Secondary & $29(7.20)$ \\
\hline & Tertiary & $319(79.6)$ \\
\hline & Others & $52(13)$ \\
\hline \multirow{2}{*}{ Marital status } & Single & $6(1.5)$ \\
\hline & Married & 395(98.5) \\
\hline \multirow{3}{*}{ Family type } & Monogamous & $334(83.3)$ \\
\hline & Polygamous & $54(13.5)$ \\
\hline & Single parenting & $13(3.2)$ \\
\hline \multirow{2}{*}{ Employment status } & Employed & $355(88.5)$ \\
\hline & Unemployed & $46(11.5)$ \\
\hline \multirow{2}{*}{ Number of children living } & Less than two children & $307(76.5)$ \\
\hline & More than two children & $94(23.5)$ \\
\hline \multirow{5}{*}{ Age of present child } & Less than 6 weeks & $94(23.4)$ \\
\hline & 7 weeks-3 months & $99(24.7)$ \\
\hline & >3 months -6 months & $132(32.9)$ \\
\hline & $>6$ months -9 months & $61(15.3)$ \\
\hline & >9 months-12 months & $15(3.7)$ \\
\hline \multirow{2}{*}{ Previously lost a child } & Yes & $28(6.9)$ \\
\hline & No & $373(93.0)$ \\
\hline \multirow{2}{*}{ Had support for childcare } & Yes & $203(50.6)$ \\
\hline & No & $198(49.4)$ \\
\hline \multirow{2}{*}{ Had the desired gender at birth } & Yes & $348(86.8)$ \\
\hline & No & $53(13.2)$ \\
\hline
\end{tabular}




\begin{tabular}{|c|c|c|}
\hline \multicolumn{2}{|l|}{ Variables } & \multirow{2}{*}{$\begin{array}{c}\text { No. (\%) } \\
352(87.8)\end{array}$} \\
\hline & Yes & \\
\hline Agreement with partner in making major decisions & No & $49(12.2)$ \\
\hline \multirow{2}{*}{ Agreement with a partner concerning family finances } & Yes & $354(88.3)$ \\
\hline & No & $47(11.7)$ \\
\hline \multirow{2}{*}{ Agreement with partner in ways of dealing with in-laws } & Yes & $322(80.3)$ \\
\hline & No & 79(19.7) \\
\hline \multirow{3}{*}{ Level of relationship satisfaction } & Poor & $6(1.5)$ \\
\hline & Moderate & $49(12.2)$ \\
\hline & Good & $346(86.3)$ \\
\hline \multirow{2}{*}{ Illness during pregnancy } & Yes & $85(21.2)$ \\
\hline & No & $316(78.8)$ \\
\hline \multirow{2}{*}{ Complications at birth } & Yes & $30(7.5)$ \\
\hline & No & $371(92.5)$ \\
\hline \multirow{3}{*}{ Mode of delivery } & Vagina & 235(57.9) \\
\hline & $\mathrm{C} / \mathrm{S}$ & 164(40.6) \\
\hline & Forceps & $2(1.5)$ \\
\hline \multirow{2}{*}{ Medical history of depression pre-pregnancy } & Yes & $30(7.5)$ \\
\hline & No & $371(92.5)$ \\
\hline
\end{tabular}

* Others include Edo, Hausa, Delta; $<$ (less than), $>$ (greater than),$\geq$ (greater than or equal to)

MPA

activity was quite high (72.1\%). Although there was no exact study measuring physical activity in postpartum women in Nigeria, two Nigerian studies reported $79 \%$ [31] and 52.2\% [32] of postnatal exercises engagement with activity participation differing from this study. Other foreign studies have shown lower physical activity levels $[18,33]$. High levels of physical activity in this study could be due to the economic terrain, which necessitates a woman getting back to work shortly after while joggling home care, and also because a one-year study duration was used. Physical activity was found to be lesser in the immediate postpartum period and increased constantly throughout the postpartum period. This may also have influenced the high rate reported. The increasing levels of physical activity down the postpartum period may reflect the reduction in help and support earlier received and more women being comfortable participating in physical activity. This was similarly reported by Borodulin et al. [34]. Women think it unsafe to participate in physical activity earlier than three months postpartum [32].

There was no statistically significant association between PPD and physical activity levels in this study. This

Table 2. Association between postpartum depression and physical activity

\begin{tabular}{cccccc}
\hline Variables & \multicolumn{2}{c}{ PPD, No. (\%) } & Unadj OR & 95\%Cl & P \\
\hline Physical Activity* & Yes & No & & & \\
\hline Physical activity & $116(40.1)$ & $173(59.9)$ & & & 0.327 \\
\hline Low physical activity & $39(34.8)$ & $73(65.2)$ & 1.255 & $0.797-0.97$ & \\
\hline
\end{tabular}

*Physical activity included high and moderate scores. 
Table 3. Association between Postpartum depression and socio-demographic factors

\begin{tabular}{|c|c|c|c|c|}
\hline \multirow{2}{*}{\multicolumn{2}{|c|}{ Variables }} & \multicolumn{2}{|c|}{ PPD ( $\geq 10)$, No.(\%) } & \multirow{2}{*}{$\mathbf{P}$} \\
\hline & & Yes & No & \\
\hline \multirow{4}{*}{ Maternal age } & $<25$ & $4(34.6)$ & $7(63.6)$ & \multirow{4}{*}{0.912} \\
\hline & $25-29$ & $38(35.8)$ & $68(64.2)$ & \\
\hline & $30-34$ & 69(39.9) & $104(60.1)$ & \\
\hline & $\geq 35$ & $44(39.6)$ & $67(60.4)$ & \\
\hline \multirow{3}{*}{ Education } & Secondary & $14(48.3)$ & $15(51.7)$ & \multirow{3}{*}{0.540} \\
\hline & Tertiary & $121(37.9)$ & 198(62.1) & \\
\hline & Others & $20(38.5)$ & $32(61.5)$ & \\
\hline \multirow{2}{*}{ Employment } & Employed & $138(38.9)$ & $217(61.1)$ & \multirow{2}{*}{0.802} \\
\hline & Unemployed & $17(37)$ & $29(63)$ & \\
\hline \multirow{3}{*}{ Family type } & Polygamous & $34(63)$ & $20(37)$ & \multirow{3}{*}{$0.000^{*}$} \\
\hline & Monogamous & $115(34.4)$ & $219(65.6)$ & \\
\hline & Single parenting & $6(46.2)$ & $7(53.8)$ & \\
\hline \multirow{2}{*}{ Religion } & Christian & $124(36.8)$ & $213(63.2)$ & \multirow{2}{*}{0.105} \\
\hline & Islam & $30(47.6)$ & $33(52.4)$ & \\
\hline \multirow{2}{*}{ Marital status } & Married & $4(66.7)$ & $2(33.3)$ & \multirow{2}{*}{0.156} \\
\hline & Single & $151(38.2)$ & $244(61.8)$ & \\
\hline \multirow{2}{*}{ Had support for child } & Yes & $72(35.6)$ & $130(64.4)$ & \multirow{2}{*}{0.220} \\
\hline & No & $82(41.6)$ & $115(58.4)$ & \\
\hline \multirow{2}{*}{$\begin{array}{c}\text { Number of children } \\
\text { living }\end{array}$} & Less than 2 & $109(35.5)$ & $198(64.5)$ & \multirow{2}{*}{$0.019 *$} \\
\hline & More than 2 & $46(48.9)$ & $48(51.1)$ & \\
\hline \multirow{2}{*}{$\begin{array}{l}\text { Have you previously lost } \\
\text { a child }\end{array}$} & Yes & $14(53.8)$ & $12(46.2)$ & \multirow{2}{*}{0.413} \\
\hline & No & $231(61.9)$ & $142(38.1)$ & \\
\hline \multirow{5}{*}{ Age of present child } & $<6$ weeks & $33(35.1)$ & $61(64.9)$ & \multirow{5}{*}{$0.025^{*}$} \\
\hline & 6 weeks-3mths & $29(29.3)$ & $70(70.7)$ & \\
\hline & $>3$ mths -6 mths & $59(44.7)$ & $73(55.3)$ & \\
\hline & $>6$ mths-9mths & $24(39.3)$ & $37(60.7)$ & \\
\hline & $>9$ mths -12 mths & $10(66.7)$ & $5(33.3)$ & \\
\hline \multirow{2}{*}{$\begin{array}{l}\text { Had Desired child } \\
\text { gender }\end{array}$} & Yes & $72(20.8)$ & $274(79.2)$ & \multirow{2}{*}{$0.026 *$} \\
\hline & No & $18(34.6)$ & $34(65.4)$ & \\
\hline \multirow{2}{*}{ Illness during pregnancy } & Yes & $39(46.4)$ & $45(53.6)$ & \multirow{2}{*}{0.183} \\
\hline & No & $121(38.4)$ & 194(61.6) & \\
\hline \multirow[b]{2}{*}{ Mode of delivery } & Yes & $91(39.2)$ & $141(60.8)$ & \multirow{2}{*}{0.717} \\
\hline & No & $61(37.4)$ & $102(62.6)$ & \\
\hline
\end{tabular}




\begin{tabular}{|c|c|c|c|c|}
\hline \multirow{2}{*}{\multicolumn{2}{|c|}{ Variables }} & \multicolumn{2}{|c|}{ PPD ( $\geq 10)$, No.(\%) } & \multirow{2}{*}{$\mathbf{P}$} \\
\hline & & Yes & No & \\
\hline \multirow{2}{*}{ Complication at birth } & Yes & $15(50)$ & $15(50)$ & \multirow{2}{*}{0.176} \\
\hline & No & $138(37.5)$ & $230(62.5)$ & \\
\hline \multirow{2}{*}{$\begin{array}{l}\text { Medical history of de- } \\
\text { pression pre-pregnancy }\end{array}$} & Yes & $15(53.6)$ & $13(46.4)$ & \multirow{2}{*}{0.086} \\
\hline & No & $137(37.2)$ & $231(62.8)$ & \\
\hline \multirow{2}{*}{$\begin{array}{l}\text { Agreement with your } \\
\text { partner concerning fam- } \\
\text { ily finances }\end{array}$} & Yes & $128(36.3)$ & $225(63.7)$ & \multirow{2}{*}{$0.026^{*}$} \\
\hline & No & $24(53.3)$ & $21(46.7)$ & \\
\hline \multirow{2}{*}{$\begin{array}{l}\text { Agreement with your } \\
\text { partner in ways of deal- } \\
\text { ing with in-laws }\end{array}$} & Yes & $112(35)$ & $208(65)$ & \multirow{2}{*}{$0.008^{*}$} \\
\hline & No & $40(51.3)$ & $38(48.7)$ & \\
\hline \multirow{2}{*}{$\begin{array}{l}\text { Agreement with partner } \\
\text { in decision making }\end{array}$} & Yes & $128(36.6)$ & $222(63.4)$ & \multirow{2}{*}{$0.008^{*}$} \\
\hline & No & $24(50)$ & $24(50)$ & \\
\hline \multirow{2}{*}{ Relationship satisfaction } & Poor/moderate & $33(63.5)$ & 19(36.5) & \multirow{2}{*}{$0.0001^{*}$} \\
\hline & Good & $118(34.2)$ & $226(65.7)$ & \\
\hline
\end{tabular}

*Significant level of 0.01

was similarly reported by Daley et al. and Saligheh, et al. $[7,35]$. The latter was a cross-sectional study assessing physical activity and PPD amongst women from postpuerperal to the first-year post-delivery, similar to this present study. Other studies however reported exercise to be effective in preventing and treating mild to moderate depression [19, 20, 36-39]. These studies were either experimental or a review of the literature. Although there was no significant association, high physical activity increased the chances of developing PPD symptoms compared to lower levels of physical activity. This finding is buttressed by Demissie et al. who reported women who had high levels of physical activity had twice the risk of developing elevated depressive symptoms [18]. High physical activity in this study involved vigorous exercises, which were household activities and walking than activities performed for leisure. It has been reported that leisure/outdoor physical activity reduces PPD compared to activities due to childcare or household work $[18,40]$.

Age of child, which is illustrative of the postpartum period was significantly associated with PPD. Mothers with younger babies were less likely to have PPD compared to older babies. This finding is similar to that of Saligheh et al. and Shorey et al. $[35,41]$. Shorey et al. who reviewed the literature using healthy women noted a general increasing prevalence with the age of the child. Age of child, which is a proxy for the postpartum period, was associated with an increase in the prevalence of PPD as the period progresses. Bugdayci, et al. reported that
PPD prevalence increased from $29 \%$ (0-2 months) to $36 \%$ (7-12 months) and higher above 13 months [42]. This increase in PPD may account for higher outcomes of PPD in later postpartum periods than earlier ones $[2,43]$. With the significant waning of physical, financial, and emotional support from friends and family coupled with the mother's full participation in home activities, childcare, employment, and/or business, one might see how this could account for increased PPD.

Most studies have found a positive association between relationship satisfaction and PPD, and this study was not any different. Whilst marital satisfaction has been suggested as a mild predictor of PPD, its effect is majorly based on the perceived level of physical, financial, and emotional support the woman receives in the relationship [3, 44, 45]. This same perceived satisfaction can be connected to the effect family setting has on PPD. In this study, the family setting was independently associated with PPD with polygamy conferring a three-fold increase in PPD than women in monogamous marriage. This finding is similarly reported in other studies done in traditional societies $[45,46]$. In contrast, Ghosh and Goswami and Rahman et al. found that women coming from nuclear families suffer more from PPD [47, 48]. The quality of the relationship with the husband and the type of support received could determine the impact of family setting on postpartum symptoms. 
Table 4. Multivariate analysis

\begin{tabular}{|c|c|c|c|c|}
\hline \multicolumn{2}{|c|}{ Variable } & \multirow{2}{*}{$\begin{array}{c}\text { Adjusted OR } \\
0.310\end{array}$} & \multirow{2}{*}{$\begin{array}{c}95 \% \mathrm{Cl} \\
0.085-1.128\end{array}$} & \multirow{2}{*}{$\begin{array}{c}\mathbf{P} \\
0.050^{*}\end{array}$} \\
\hline \multirow{5}{*}{ Child age } & $<6$ weeks & & & \\
\hline & 6wks-3mths' & 0.248 & $0.069-0.892$ & $0.033^{*}$ \\
\hline & $3 m$ ths $-6 m$ ths & 0.450 & $0.130-1.561$ & 0.208 \\
\hline & 6mths-9mths & 0.438 & $0.120-1.599$ & 0.211 \\
\hline & $>9$ months & 1 & & 0.143 \\
\hline \multirow{3}{*}{ Family type } & Polygamy & 3.491 & $1.832-6.650$ & $0.000^{*}$ \\
\hline & Single parenting & 0.660 & $0.143-3.067$ & 0.594 \\
\hline & Monogamy & 1 & & $0.001^{*}$ \\
\hline \multirow{2}{*}{ Desired gender } & Yes & 0.466 & $0.237-0.916$ & $0.027^{*}$ \\
\hline & No & 1 & & \\
\hline \multirow{2}{*}{ Relationship satisfaction } & Poor/moderate & 2.776 & $105 r-5$ & SO ${ }^{*}$ \\
\hline & Good & 1 & $1.300-3.042$ & 0.005 \\
\hline \multirow{3}{*}{ Physical activity } & Low & 1 & & 0.232 \\
\hline & Moderate & 0.728 & $0.412-1.288$ & 0.276 \\
\hline & High & 1.144 & $0.625-2.096$ & 0.663 \\
\hline \multirow{2}{*}{$\begin{array}{l}\text { Do you agree with your } \\
\text { partner concerning fam- } \\
\text { ily finances }\end{array}$} & Yes & 1.289 & \multirow{2}{*}{$0.562-2.956$} & \multirow{2}{*}{0.549} \\
\hline & No & 1 & & \\
\hline \multirow{2}{*}{$\begin{array}{l}\text { Do you agree with your } \\
\text { partner in making major } \\
\text { decisions }\end{array}$} & Yes & 0.583 & \multirow{2}{*}{$0.274-1.240$} & \multirow{2}{*}{0.161} \\
\hline & No & 1 & & \\
\hline \multirow{2}{*}{$\begin{array}{l}\text { Do you agree with } \\
\text { partner in dealing with } \\
\text { in-laws }\end{array}$} & Yes & 0.931 & \multirow{2}{*}{$0.479-1.808$} & \multirow{2}{*}{0.832} \\
\hline & No & 1 & & \\
\hline \multirow{2}{*}{$\begin{array}{l}\text { Number of children } \\
\text { living }\end{array}$} & $<2$ & 0.640 & \multirow{2}{*}{$0.378-1.083$} & \multirow{2}{*}{0.097} \\
\hline & $>2$ & 1 & & \\
\hline \multirow{2}{*}{$\begin{array}{l}\text { Medical history of } \\
\text { depression }\end{array}$} & Yes & 1.492 & \multirow{2}{*}{$0.610-3.647$} & \multirow{2}{*}{0.381} \\
\hline & No & 1 & & \\
\hline
\end{tabular}

"Significance set at 0.05

IRA

Gender of the child was a positive risk factor for PPD. This is similar to other studies done both in Nigeria [11] and other traditional societies [44, 49] where the husband's or even the wife's disappointment with the gender of the baby is significantly associated with developing PPD, specifically if the baby is a girl. This is especially seen if the woman already had a female child. Most Africans have this preference for male children as heirs and progenitors of the family put pressure on the woman. Comparably, in some western studies, a similar relationship did not exist between the gender of the child and PPD [29, 50].

\section{Conclusion}

PPD is prevalent here in Nigeria and is generally higher than the speculated $10 \%-15 \%$. It is a global health issue that should be taken seriously as it cuts across both low- and high-income countries and associated factors are dependent upon cultural and socio-economic terrain. It is no longer a myth that can be swept under the carpet but should be openly addressed and necessary systems put in place, especially in tertiary hospitals that attends to a mix of mothers in the society, in other to enable healthier, happier families. This study hopes to encourage further research in this direction. 


\section{Limitations}

A standard scale was not used to assess relationship satisfaction; therefore, the results should be interpreted with caution. Also, as a cross-sectional study, I could not determine the temporal association between PPD and physical activity. The study population was a mix of people, the sample population may not reflect this diversity as most were educated, consequently, a generalization must be carefully made.

\section{Ethical Considerations}

\section{Compliance with ethical guidelines}

Approval for the study was sought from the University of Ibadan / University College Hospital Health Research Ethics Committee (UI/UCH/EC/16/0103). Permission was also sought from the authorities of the immunization clinic (Institute of child health, UCH) and postnatal clinic (obstetrics and gynecology department, UCH), where the study was carried out. Written informed consent was obtained from respondents after informing them of the purpose, intent, voluntary participation, and non-maleficence of the survey. Confidentiality was maintained in the questionnaire by keeping them anonymous.

\section{Funding}

This research did not receive any grant from funding agencies in the public, commercial, or non-profit sectors.

\section{Authors' contributions}

All authors equally contributed to preparing this article.

\section{Conflict of interest}

The authors declared no conflict of interest.

\section{Acknowledgments}

I want to acknowledge the support received from my Supervisor, Dr. Pelumi Adebiyi, and the management, staff, and women who attended the Immunisation and postnatal clinics of a University college hospital, Ibadan, and were generous with their time.

\section{References}

[1] Hewitt CE, Gilbody S, Brealey S, Paulden M, Palmer S, Mann R, et al. Methods to identify postnatal depression in primary care: An integrated evidence synthesis and value of information analysis. Health Technol Assess. 2009; 13(36):1-145. [DOI:10.3310/ hta13360] [PMID]

[2] World Health Organization (WHO). Depression and other common mental disorders: Global health estimates [Internet]. 2017 [Updated 2017]. Available from: https://apps.who.int/iris/handle/10665/254610

[3] Norhayati MN, Hazlina NN, Asrenee AR, Wan Emilin WMA. Magnitude and risk factors for postpartum symptoms: A literature review. J Affect Disord. 2015; 175:34-52. [DOI:10.1016/j. jad.2014.12.041] [PMID]

[4] Stewart DE, Robertson E, Dennis CL, Grace SL, Wallington T. Postpartum depression: Literature review of risk factors and interventions [Internet]. 2003. [Updated 2003]. Available from: https://poliklinika-harni.hr/images/uploads/380/who-postpartalna-depresija.pdf

[5] Goodman JH. Postpartum depression beyond the early postpartum period. J Obstet Gynecol Neonatal Nurs. 2006; 33(4):410 20. [DOI:10.1177/0884217504266915] [PMID]

[6] Leitch S. Postpartum depression: A review of the literature. St. Thomas, Ontario: Elgin-St. Thomas Health Unit. 2002.

[7] Daley A, Winter H, Grimmett C, McGuinness M, McManus R, MacArthur C. Feasibility of an exercise intervention for women with postnatal depression: A pilot randomised controlled trial. $\mathrm{Br}$ J Gen Pract. 2008; 58)548):178-83. [DOI:10.3399/bjgp08X277195] [PMID] [PMCID]

[8] Hahn-Holbrook J, Cornwell-Hinrichs T, Anaya I. Economic and health predictors of national postpartum depression prevalence: A systematic review, meta-analysis, and meta-regression of 291 studies from 56 countries. Front Psychiatry. 2018; 8:248. [DOI:10.3389/fpsyt.2017.00248] [PMID] [PMCID]

[9] Fisher J, de Mello MC, Patel V, Rahman A, Tran T, Holton S, et al. Prevalence and determinants of common perinatal mental disorders in women in low and lower-middle-income countries: A systematic review. Bull World Health Organ. 2012; 90(2):139H49H. [DOI:10.2471/BLT.11.091850] [PMID] [PMCID]

[10] Gureje O, Oladeji BD, Araya R, Montgomery AA, Kola L, Kirmayer L, et al. Expanding care for perinatal women with depression (EXPONATE): Study protocol for a randomized controlled trial of an intervention package for perinatal depression in primary care. BMC Psychiatry. 2015; 15:136. [DOI:10.1186/s12888015-0542-6] [PMID] [PMCID]

[11] Abiodun OA. Postnatal depression in primary care populations in Nigeria. Gen Hosp Psychiatry. 2006; 28(2):133-6 [DOI:10.1016/j.genhosppsych.2005.11.002] [PMID]

[12] Dennis CL, Chung-Lee L. Postpartum depression help-seeking barriers and maternal treatment preferences: A qualitative systematic review. Birth. 2006; 33(4):323-31. [DOI:10.1111/j.1523536X.2006.00130.x] [PMID] [PMCID]

[13] Eberhard-Gran M, Eskild A, Opjordsmoen S. Use of psychotropic medications in treating mood disorders during lactation: Practical recommendations. CNS Drugs. 2006; 20(3):187-98. [DOI:10.2165/00023210-200620030-00002] [PMID]

[14] Fitelson E, Kim S, Baker AS, Leight K. Treatment of postpartum depression: Clinical, psychological and pharmacological options. Int J Womens Health. 2010; 3:1-14. [DOI:10.2147/ IJWH.S6938] [PMID] [PMCID] 
[15] Wisner KL, Perel JM, Peindl KS, Hanusa BH, Findling RL, Rapport D. Prevention of recurrent postpartum depression: A randomized clinical trial. J Clin Psychiatry. 2001; 62(2):82-6. [DOI:10.4088/JCP.v62n0202] [PMID]

[16] Kołomańska-Bogucka, D, Mazur-Bialy AI. Physical activity and the occurrence of postnatal depression-a systematic review. Medicina (Kaunas). 2019; 55(9):560. [DOI:10.3390/medicina55090560] [PMID] [PMCID]

[17] Bahadoran P, Tirkesh F, Oreizi HR. Association between physical activity 3-12 months after delivery and postpartum well-being. Iran J Nurs Midwifery Res. 2014; 2(1):82-7. [PMID] [PMCID]

[18] Demissie Z, Siega-Riz AM, Evenson KR, Herring AH, Dole $\mathrm{N}$, Gaynes BN. Associations between physical activity and postpartum depressive symptoms. J Womens Health (Larchmt). 2011; 20(7):1025-34. [DOI:10.1089/jwh.2010.2091] [PMID] [PMCID]

[19] Dunn AL, Trivedi MH, Kampert JB, Clark CG, Chambliss HO. The DOSE study: A clinical trial to examine efficacy and dose response of exercise as treatment for depression. Control Clin Trials. 2002; 23(5):584-603. [DOI:10.1016/S01972456(02)00226-X] [PMID]

[20] Okyay EK, Ucar T. The effect of physical activity level at postpartum period on quality of life and depression level. Med Sci Int Med J. 2018; 7(3):587-93. [DOI:10.5455/medscience.2018.07.8822]

[21] Ukaegbe CI, Iteke OC, Bakare MO, Agbata AT. Postpartum depression among igbo women in an urban mission hospital South East Nigeria. Ebonyi Med J. 2012; 11(1 \& 2):29-36. https://www.researchgate.net/ profile/Muideen-Bakare/publication/259487287

[22] Adewuya AO, Eegunranti AB, Lawal AM. Prevalence of postnatal depression in Western Nigerian women: A controlled study. Int J Psychiatry Clin Pract. 2005; 9(1):60-4 [DOI:10.1080/13651500510018211] [PMID]

[23] Oyeyemi AL, Oyeyemi Ay, Adegoke BO, Oyetoke, FO, Aliyu HN, Aliyu Su, et al. Cross cultural adaptation of the International Physical Activity Questionnaire: Reliability and validity of the Hausa version in Nigeria. BMC Med Res Methodol. 2011; 11:156. [DOI:10.1186/1471-2288-11-156] [PMID] [PMCID]

[24] Agbaje OS, Anyanwu JI, Umoke PI, Iwuagwu TE, Iweama $\mathrm{CN}$, Ozoemena, EL et al. Depressive and anxiety symptoms and associated factors among postnatal women in EnuguNorth Senatorial District, South-East Nigeria: A cross-sectional study. Arch Public Health. 2019; 77:1. [DOI:10.1186/s13690018-0329-6] [PMID] [PMCID]

[25] Obindo TJ, Ekwempu CC, Ocheke AN, Piwuna CG, Adegbe EO, Omigbodun OO. Prevalence and correlates of postpartum depression in a teaching hospital in Nigeria. Highland Med Res J. 2013; 13(2):71-5. https://www.ajol.info/index.php/ $\mathrm{hmrj/article/view/109793}$

[26] Sulyman D, Ayanda KA, Dattijo LM, Aminu BM. Postnatal depression and its associated factors among Northeastern Nigerian women. Ann Trop Med Public Health. 2016; 9(3):184-90. [DOI:10.4103/1755-6783.179099]

[27] Uwakwe R, Okonkwo JEN. Affective (depressive) morbidity in puerperal Nigerian women: Validation of the Edinburgh postnatal depression scale. Acta Psychiatr Scand. 2003; 107(4):251-9. [DOI:10.1034/j.1600-0447.2003.02477.x] [PMID]
[28] Parsons CE, Young KS, Rochat TJ, Kringelbach ML, Stein A. Postnatal depression and its effects on child development: A review of evidence from low- and middle-income countries. Br Med Bull. 2012; 101:57-79. [DOI:10.1093/bmb/ ldr047] [PMID]

[29] Josefsson A. Postpartum depression- epidemiological and biological aspects. [MD. dissertation]. Linköping: Linköping University; 2003. https://www.diva-portal.org/smash/record.jsf?pid=diva2 $\% 3 \mathrm{~A} 21141 \&$ dswid= $=-7004$

[30] Lanes A, Kuk JL, Tamim H. Prevalence and characteristics of Postpartum Depression symptomatology among Canadian women: A cross-sectional study. BMC Public Health. 2011;11:302. [DOI:10.1186/1471-2458-11-302] [PMID] [PMCID]

[31] Mbada CE, Adebayo OE, Awotidebe TO, Faremi FA, Oginni MO, Ogundele AO, et al. Practice and pattern of antenatal and postnatal exercise among Nigerian Women: A cross sectional study. Int J Womens Health Reprod Sci. 2015: 3(2):93-8 [DOI:10.15296/ijwhr.2015.18]

[32] Adeniyi AF, Ogwumike OO, Bamikefa TR. Postpartum exercise among Nigerian women: Issues relating to exercise performance and self-efficacy. ISRN Obstet Gynecol. 2013; 2013:294518. [DOI:10.1155/2013/294518] [PMID] [PMCID]

[33] Juř́ková J, Havelka R. Physical activity in puerperium period. Eur Proc Soc Behav Sci. 2019; 18:55. [DOI:10.15405/ epsbs.2019.02.37]

[34] Borodulin K, Evenson KR, Herring AH. Physical activity patterns during pregnancy through postpartum. BMC Womens Health. 2009; 9:32 [DOI:10.1186/1472-6874-9-32] [PMID] [PMCID]

[35] Saligheh M, Rooney RM, McNamara B, Kane RT. The relationship between postnatal depression, sociodemographic factors, levels of partner support, and levels of physical activity. Front Psychol 2014; 5:597. [DOI:10.3389/fpsyg.2014.00597] [PMID] [PMCID]

[36] Armstrong K, Edwards H. The effects of exercise and social support on mothers reporting depressive symptoms: A pilot randomized controlled trial. Int J Mental Health Nurs. 2003; 12(2):130-8. [DOI:10.1046/j.1440-0979.2003.00229.x] [PMID]

[37] Da Costa D, Lowensteyn I, Abrahamowicz M, Ionescu-Ittu R, Dritsa M, Rippen N, et al. A randomized clinical trial of exercise to alleviate postpartum depressed mood. J Psychosom Obstet Gynaecol. 2009; 30(3):191-200. [DOI:10.1080/01674820903212136] [PMID]

[38] Daley AJ, Blamey RV, Jolly K, Roalfe AK, Turner KM, Coleman S, et al. A pragmatic randomized controlled trial to evaluate the effectiveness of a facilitated exercise intervention as a treatment for postnatal depression: The PAMPeRS trial. Psychol Med. 2015; 45(11):2413-25. [DOI:10.1017/ S0033291715000409] [PMID]

[39] Kołomańska-Bogucka D, Mazur-Bialy AI. Physical activity and the occurrence of postnatal depression-a systematic review. Medicina. 2019; 55(9):560. [DOI:10.3390/medicina55090560]

[40] Teychenne M, York R. Physical activity, sedentary behavior, and postnatal depressive symptoms: A review. Am J Prev Med. 2013; 45(2):217-27. [DOI:10.1016/j.amepre.2013.04.004] [PMID] 
[41] Shorey S, Ing Chee CY, Ng ED, Chan YH, San Tam WW, Chong YS. Prevalence and incidence of postpartum depression among healthy mothers: A systematic review and metaanalysis. J Psychiatr Res. 2018; 104:235-48. [DOI:10.1016/j. jpsychires.2018.08.001] [PMID]

[42] Bugdayci R, Tayyar Sasmaz C, Tezcan H, Kurt AO, Öner $\mathrm{S}$. A cross-sectional prevalence study of depression at various times after delivery in Mersin province in Turkey. J Womens Health (Larchmt). 2004; 13(1):63-8. [DOI:10.1089/1540999043 22836465] [PMID]

[43] Chandran M, Tharyan P, Muliyil J, Abraham S. Post-partum depression in a cohort of women from a rural area of Tamil Nadu, India: Incidence and risk factors. Br J Psychiatry. 2002; 181:499-504. [DOI:10.1192/bjp.181.6.499] [PMID]

[44] Patel V, Rodrigues M, DeSouza N. Gender, poverty, and postnatal depression: A study of mothers in Goa, India. Am J Psychiatry. 2002; 159(1):43-7. [DOI:10.1176/appi.ajp.159.1.43] [PMID]

[45] Fatoye FO, Oladimeji BY, Adeyemi AB. Difficult delivery and some selected factors as predictors of early postpartum psychological symptoms among Nigerian women. J Psychosom Res. 2006; 60(3):299-301. [DOI:10.1016/j.jpsychores.2005.04.012] [PMID]

[46] Ho-Yen SD, Tschudi Bondevik G, Eberhard-Gran M, Bjorvatn B. Factors associated with depressive symptoms among postnatal women in Nepal. Acta Obstet Gynecol Scand. 2007; 86:291-7. [DOI:10.1080/00016340601110812] [PMID]

[47] Ghosh A, Goswami S. Evaluation of postpartum depression in a tertiary hospital. J Obstet Gynaecol India. 2011; 61(5):52830. [DOI:10.1007/s13224-011-0077-9] [PMID] [PMCID]

[48] Rahman A, Iqbal Z, Harrington R. Life events, social support and depression in childbirth: Perspectives from a rural community in the developing world. Psychol Med. 2003; 33(7):1161-7. [DOI:10.1017/S0033291703008286] [PMID]

[49] Nakku JEM, Nakasi G, Mirembe F. Postpartum major depression at six weeks in primary health care: Prevalence and associated factors. Afr Health Sci. 2006; 6(4):207-14. [DOI:10.5555/afhs.2006.6.4.207] [PMID] [PMCID]

[50] Robertson E, Celasun N, and Stewart DE. Risk factors for postpartum depression. In Stewart DE, Robertson E, Dennis C.L, Grace SL, \& Wallington T. Postpartum depression: Literature review of risk factors and interventions. University Health Network Women's Health Program; 2003. https:// www.who.int/mental_health/prevention/suicide/lit_review_postpartum_depression.pdf 